\title{
Anxiety among Up Board Students in Uttar Pradesh, India
}

\author{
Jaya Bharti ${ }^{1 *}$
}

\section{ABSTRACT}

Background: The present study aims to investigate the anxiety level of sports and non-sports students during board exam. It also aimed to find out the difference of anxiety among up board students on the basis of gender and the difference of anxiety among up board students on the basis of socio-economic status. These were studied with respect to different demographic variables like school type, socio-economic background, gender and academic stream. Methods: In this study, Sample included 420 randomly selected students i.e. 210 boys and 210 girls of U.P boards from various schools of Education at Uttar Pradesh. Subjects were assessed using Sociodemographic sheet and Anxiety Scale by Sinha \& Sinha (1955). Result: The results of the study revealed considerable anxiety in boys than girls $(\mathrm{p}<0.01)$. Students from Hindi medium schools were more anxious than students from English medium schools $(p<0.01)$. Students belonging to the middle class (middle socio-economic group) suffered more anxiety than those from both high and low socio-economic groups $(\mathrm{p}<0.01)$. Conclusion: conclusion is that Parent child relationship, child and teacher relationship and parent and teacher relationship and support decrease the level of anxiety. Parents and teacher emotional support drastically change the statics of anxiety in students. Parents and teacher use anxiety prevention efforts and gave lots of confidence to the child because these steps only weapon who broke the anxiety stone.

Keywords: Anxiety, U.P Board Students, Exam Anxiety, Overcome Strategies, Counselling

The state of Uttar Pradesh in India has a rich history of education and learning. It was from the beginning of the Vedic period in India that Uttar Pradesh was the chosen destination for education. Languages like Sanskrit, Persian and Arabic were first taught in this part of the country during the Gupta rule. Therefore, long before the British settled in India, Uttar Pradesh had established a name for itself as the education hub of the country. It was after the settlement of the British that the quality of education in Uttar Pradesh witnessed a decline as the state authorities could not match up to the western standards of education already followed in several other parts of the country. The British can be credited for erecting a number of colleges and universities in Uttar Pradesh to promote education following the western pattern. The concept of

\footnotetext{
${ }^{1}$ JRF, Lucknow University, Uttar Pradesh

*Responding Author

(C) 2016 I J Bharti; licensee IJIP. This is an Open Access Research distributed under the terms of the Creative Commons Attribution License (http://creativecommons.org/licenses/by/2.0), which permits unrestricted use, distribution, and reproduction in any Medium, provided the original work is properly cited.
} 


\section{Anxiety among Up Board Students in Uttar Pradesh, India}

an elaborate school and college education introduced by the British was carried forward by the state government authorities post-independence. Children and women education was promoted by the colonial rulers in India and ever since, the education system of Uttar Pradesh has seen an uphill graph. According to the census reports published in the year 2011, the literacy rate in the state is $69.72 \%$. This is a noticeable improvement when compared to the literacy rate of $56.27 \%$ recorded in the year 2001.

The Board of High School and Intermediate Education Uttar Pradesh is the Pradesh state government administered autonomous examining authority for the Standard 10 examination (or secondary school level examination) and Standard 12 examination (or inter college level examination) of Uttar Pradesh, India. The examination for the 10th and 12th standard is called the High school examination and Intermediate examination respectively. The High school and Intermediate examination is conducted annually and simultaneously all over the State of Uttar Pradesh. Presently, the Board is holding the examinations and preparing the results of nearly 32, 00,000 students. It has its headquarters at Allahabad. In India, the main documented cause of anxiety among school children and U.P boards is parents' high educational expectations and pressure for academic achievement (Deb, 2001). In India, this is amplified in secondary school where all 16-year old children attempt the Class X first Board Examination, known as the Secondary Examination. Results of the Secondary Examination are vital for individuals since this is the main determining criteria for future admission to a high quality senior secondary school and a preferred academic stream. There is fierce competition among students since the number of places in these educational institutions is fewer than the number of students. Therefore, parents urge their children to perform well in the first Board Examination and, to this end they may appoint three to four private tutors or more for special guidance. After the Secondary Examination, all students appear in the Class XII Final Board Examination known as the Higher Secondary Examination. Competition is again ferocious as performance in this examination determines university entrance. Admission to courses in Medicine, Engineering and Management are the most preferred choices for parents because these qualifications are seen to guarantee future job prospects. It is relevant to mention here that in one year alone in India, 2320 children, or more than six children per day, committed suicide because of failure in examinations (National Crime Records Bureau, Ministry of Home Affairs, Government of India, 2000). After the Secondary Examination, all students appear in the Class XII Final Board Examination known as the Higher Secondary Examination. Competition is again ferocious as performance in this examination determines university entrance. Admission to courses in Medicine, Engineering and Management are the most preferred choices for parents because these qualifications are seen to guarantee future job prospects. It is relevant to mention here that in one year alone in India, 2320 children, or more than six children per day, committed suicide because of failure in examinations (National Crime Records Bureau, Ministry of Home Affairs, Government of India, 2000).

\section{Operational Definition:}

Anxiety - Anxiety, thus, is a state of being troubled and uneasy. Anxiety has two major worksfirst, it warns against the problems that are to come in life and enables an individual to act and 
eliminate the experiences of pain. Second, anxiety indicates the problems which cause pain to the soul. Many people confuse anxiety with fear. However, fear is something that can be in front of you (i.e., a real danger), whereas anxiety is the paranoia of something out there that seems menacing but it may not be menacing, and indeed may not even be out there (Henig, Robin (9), The New York Times Magazine, rtvd. on 10 December 2012).

\section{OBJECTIVES}

1. To study anxiety among U.P boards Students.

a) To find out the difference of anxiety among up board students on the basis of gender.

b) To find out the difference of anxiety among up board students on the basis of socio-economic status.

\section{Hypothesis-}

1. The anxiety of U.P board boys and girls, irrespective of medium of instruction \& socioeconomic background differs significantly.

2. The anxiety of U.P board studying in Hindi and English medium schools, irrespective of gender \& socio-economic background differs significantly.

3. The anxiety of U.P board belonging to different socio-economic backgrounds, irrespective of gender \& medium of instruction differs significantly.

\section{RESEARCH METHODOLOGY}

\section{Setting:}

U.P board schools of Uttar Pradesh.

\section{Sample:}

Participants in the study were a group of 420 students. Students studying in class $\mathrm{X}^{\text {th }}$ standard and Class XII standard. Participants were selected using a multi-stage random sampling technique such that the final sample was drawn from five Hindi medium and five English medium schools in Uttar Pradesh.

\section{Materials:}

The study tools that were used for achieving the objectives of the study were as follows:

(i) Semi-structured Questionnaire-Demographic and Socio-economic Information

\section{(ii) Anxiety Scale by Sinha \& Sinha (1955)}

\section{Ethical Issues:}

1- A fully informed consent was taken from all participants in the study prior to data collection.

2- Subjects had the right to withdraw from the study at any point of time during the course of the study.

3- The confidentiality of the subject was maintained through the course of the study and was shared with the treating team when deemed beneficial for administration.

4-The research meets the ethical guidelines, including adherence to the legal requirements of my country. 


\section{Data Analysis}

Data collected from the U.P boards were cleaned and prepared for analysis. Apart from descriptive statistics (measures of central tendency and dispersions)'t'-tests and ' $F$ '-tests were applied for verification of hypotheses.

\section{RESULTS}

Table 1: Comparison between U.P board Boys and Girls Sample Group on the basis of anxiety scores

\begin{tabular}{|c|c|c|c|c|c|c|c|}
\hline \multirow{2}{*}{$\begin{array}{l}\text { Anxiety Scores of } \\
\text { U.P boards } \\
\text { STUDENTS }\end{array}$} & \multicolumn{4}{|c|}{ Central Tendency Measures } & \multicolumn{2}{|l|}{ Deviations } & \multirow{2}{*}{$\begin{array}{l}\text { 't'-test and } \\
\text { Probabilit } \\
\text { y value }\end{array}$} \\
\hline & Mean & Median & Mode & S.D & Skewness & Kurtosis & \\
\hline $\begin{array}{l}\text { U.P board Boys } \\
(\mathrm{N}=210)\end{array}$ & 22.3 & 23.0 & 23.8 & 5.3 & -0.3 & -0.080 & \multirow[t]{2}{*}{$\begin{array}{l}-2.62 \text { and } \\
0.009 *\end{array}$} \\
\hline $\begin{array}{l}\text { U.P board Girls } \\
(\mathrm{N}=210)\end{array}$ & 20.5 & 20.0 & 18.0 & 5.1 & -0.7 & 1.37 & \\
\hline
\end{tabular}

To understand the anxiety faced by U.P boards, the SINHA anxiety scale was used. Data displayed in Table 1 show that the mean anxiety score in the case of U.P board boys (22.3) was slightly higher than for U.P board girls (20.5).

Table 2: Comparison between English and Hindi Medium School Students Medium of instruction.

\begin{tabular}{|l|l|l|l|l|l|l|l|}
\hline \multirow{2}{*}{$\begin{array}{l}\text { Anxiety Scores of U.P } \\
\text { boards students }\end{array}$} & \multicolumn{4}{|l|}{ Central Tendency Measures } & \multicolumn{2}{l|}{ Deviations } & $\begin{array}{l}\text { 't'-test and } \\
\text { Probability } \\
\text { value }\end{array}$ \\
\cline { 2 - 7 } & Mean & Median & Mode & S.D. & Skewness & Kurtosis & \\
\hline $\begin{array}{l}\text { English } \\
(\mathrm{N}=210)\end{array}$ & 22.0 & 23.0 & 23.0 & 5.9 & -0.4 & 1.3 & $\begin{array}{l}4.65 \text { and } \\
0.000 *\end{array}$ \\
\hline $\begin{array}{l}\text { Hindi } \\
(\mathrm{N}=210)\end{array}$ & 25.3 & 26.0 & 26.9 & 5.5 & -0.4 & -0.0 & \\
\hline
\end{tabular}

Comparison of anxiety between the U.P boards attending English and Hindi medium schools revealed that the mean values for the U.P boards attending Hindi medium schools (25.3) was slightly higher than that for U.P boards attending English medium schools (22.0). 
Table 3: Different Socio-economic background Socio-economic Group

\begin{tabular}{|l|l|l|l|l|l|l|l|}
\hline $\begin{array}{l}\text { Anxiety Scores of the } \\
\text { U.P boards students }\end{array}$ & \multicolumn{6}{|l|}{ Central Tendency Measures } & \multicolumn{2}{|l|}{ Deviations } & $\begin{array}{l}\text { 'F'-test } \\
\text { and } \\
\text { Probability } \\
\text { value }\end{array}$ \\
\cline { 2 - 9 } & Mean & Median & Mode & S.D. & Skewness & Kurtosis & \\
\hline High (N=160) & 22.6 & 24.5 & 24.8 & 5.5 & -0.1 & -0.1 & $42.35^{*}$ \\
Medium (N=190) & 29.0 & 28.3 & 25.0 & 8.0 & 1.2 & 1.1 & 0.00 \\
\hline Low (N=70) & 27.6 & 28.0 & 30.0 & 6.3 & 1.1 & 0.8 & 0.1 \\
\hline
\end{tabular}

The mean anxiety scores were found to be the highest for the middle socio-economic group (29.0), followed by the low socio-economic group (27.6) and then the high (22.6) socioeconomic group. The standard deviations for the high, middle and low socio-economic groups were 5.5, 8.0 and 6.3 respectively. It was observed that the ' $F$ ' value was significant at $(\mathrm{p}<.01)$.

\section{DISCUSSION}

This study measured U.P board student's anxiety across a number of dimensions because this is a very crucial phase in student life. The mean anxiety score for U.P board boys was found to be slightly higher than that for U.P board girls. Boys of U.P board suffering from high anxiety .U.P boards from Hindi medium schools were slightly more anxious than their English medium counterparts. The mean value for anxiety was found to be highest for the U.P boards belonging to the middle socio-economic class, followed by the U.P boards belonging to the lower and then the higher socio-economic class. Parent child relationship, child and teacher relationship and parent and teacher relationship and support decrease the level of anxiety. Parents and teacher emotional support drastically change the statics of anxiety. Parents and teacher gave lots of confidence to the child and self-confidence only weapon who broke the anxiety stone. To Avoid a Stress situation for the child the parents must provide right kind of motivation and a conducive environment. Parents help the child in maintaining his confidence especially when he seems discouraged by his dropping marks or grades. Do not displace your anxiety on the child. The achievement goals should be realistically set according to the child's capability. If achievement expectations are too then some children would prefer to be criticized for being lazy than being considered not good enough. So a targeted intervention strategy, as cognitive-behavioural treatment and triarchic counselling which included family, child and teacher can reduce levels of anxiety among adolescent

\section{KEY POINTS}

$\checkmark \quad$ A mild degree of anxiety and stress may be stimulating and motivating, and may help to overcome anxious situation; but high degree of anxiety may be disrupting.

$\checkmark$ Every child goes through such situations and learns to cope up with anxiety arising out of them. They are also learnt by imitation of the parents or parent figures.

$\checkmark$ Right approach and right coping strategies may stimulate an adolescent to overcome anxiety and maximize own performance in the examination. 
$\checkmark$ Common Physical reaction during exam preparations:

$\checkmark$ Muscle tension

$\checkmark$ Indigestion

$\checkmark$ Sleep difficulties

$\checkmark$ Repaid uneven or pounding heartbeat

$\checkmark$ Frequent urge to pass urine

$\checkmark$ Psychological Reaction to Stress

$\checkmark$ Feeling under pressure frustration and aggression

$\checkmark$ Feeling tense and unable to relax

$\checkmark$ Feeling mentally drained out

$\checkmark$ Fussy, gloomy or suspicious being constantly frightened or irritable

$\checkmark$ Inability to concentrate or complete the task.

$\checkmark$ The 5 "A's" for controlling the Exam anxiety: Acknowledging, Appreciating, Alleviating, Altering \& Avoiding.

$\checkmark$ Acknowledge the stress and strain because everyone faces it. In everyday life, stress manifests as mental or physical tension, which you would rather not have, recognize stress as inevitable.

$\checkmark$ Appreciating what causes your stress. Then, instead of blaming yourself or failing of cope; you end up pinpointing the real problem and tackling that.

$\checkmark$ Alleviating: the pressures are all about resorting to simple stress-busting techniques. Perhaps you have a calming visual to look at when you need a mental escape from your surroundings. Or you may relax your muscle before you go to sleep.

$\checkmark$ Altering: your lifestyle is the next step towards Exam Stress. Once you've seen the benefits of relaxation, it will encourage you to develop more permanent ways of reducing stress. If stress continues to be persistent, either you haven't tried the major stress alleviating formulae or alternately your haven't kept them up long enough to deliver the needed result.

$\checkmark$ Avoiding: last step is the toughest but also the most beneficial. You have to start avoiding stress building habits and burnouts. Avoid smoking - a serious stress builder exercise briefly but regularly, make an effort to maintaining a normal weight, eat regular balanced meals and get adequate sleep.

\section{REFERENCES}

Albano, A. M., Chorpita, B. F. \& Barlow, D. H. (2003). Childhood anxiety disorders. In E.J. Mash \& R. A. Barkley (Eds.), Child psychopathology (pp. 279-329). New York: Guilford Press

Barrett, P. M. \& Pahl, K. M. (2006). School-based intervention: Examining a universal approach to anxiety management. Australian Journal of Guidance and Counselling, 16, 55-75.

Bernsteen G.A.\& Borchardt C. M. , (1991), Anxiety Disorders of Childhood and Adolescence: A Critical Review, Journal of American Academy of Child and Adolescents Psychiatry, 39, 519-532 


\section{Anxiety among Up Board Students in Uttar Pradesh, India}

Deb, S. (2001, October). A study on the negative effects of academic stress. Paper presented at the International Seminar on Learning and Motivation, Kedah Darul Aman, Malaysia.

Howes, C. (1990). Can age of entry into child care and the quality of child care predict adjustment in kindergarten? Developmental Psychology, 26, 292-303.

Radin, N. (1982). Primary care giving and role-sharing behaviours. In M. E. Lamb (Ed.), Nontraditional Families: Parenting And Child Development. Hillsdale, NJ: Erlbaum.

Weiss, D. D. \& Last, C. G. (Eds.). (2001). Developmental variations in the prevalence and manifestations of anxiety disorders. The developmental psychopathology of anxiety (pp. 27-42). Oxford: Oxford University Press.

\section{Websites:}

http://www.bestindiaedu.com/uttarpradesh.html

http://www.cbse.nic.in/examstress.html 